\title{
Diferenciação específica entre Taenia saginata e Taenia solium por ensaio de PCR e duplex-PCR
}

\author{
Specific discrimination between Taenia saginata and Taenia solium by one \\ step PCR assay and duplex-PCR \\ Eurione Antônio Garcia da Veiga Jardim ${ }^{1}$ Guido Fontgalland Coelho Linhares ${ }^{2}$ \\ Fernando Araripe Gonçalves Torres ${ }^{3}$ José Luiz de Barros Araújo ${ }^{4}$ \\ Silvia Minharro Barbosa ${ }^{5}$
}

\section{RESUMO}

Este estudo teve como objetivo a padronização de protocolos e a seleção de novos primers para a identificação espécie-específica de Taenia saginata e Taenia solium através da reação em cadeia da polimerase (PCR) e duplex-PCR. Inicialmente, foram recuperadas seqüencias depositadas no GenBank (acesso n AB020399 para T. saginata e nं AB020395 para $\mathrm{T}$. solium) referentes ao gene da subunidade maior do ribossomo (LSU RNAr) de tenídeos. A partir do alinhamento das seqüências, um primer genérico denominado TBR-3 (5'ggcttgtttgaatggtttgacg- 3') foi selecionado de região conservada $e$, de diferentes regióes semi-conservadas, os primers específicos TBR-4 para T. saginata (5'-cgactcatgaagataaacaaggt-3') e TBR5 (5'-cggtcgaacagaccataaatct-3') e TBR-6 (5'gctactacacctaaattctaacc- 3') para T. solium. Os primers foram avaliados quanto à especificidade através da PCR empregandose DNA total (DNAt) de amostras de cisticercos e proglotes dos parasitos, previamente identificadas por critérios morfológicos. $O$ par de primers $T B R-3 / T B R-4$ permitiu a amplificação específica do fragmento esperado de $328 \mathrm{pb}$ a partir do DNAt de T. saginata. Os pares TBR-3/TBR-5 e TBR-3/TBR-6 permitiram a amplificação, respectivamente, dos fragmentos específicos de $310 \mathrm{pb}$ e 286pb a partir do DNAt de T. solium. A identidade dos produtos de PCR foi comprovada comparando-se a seqüencia dos amplicons obtidos às seqüências de referência do gene LSU RNAr registrado no GenBank ( $n^{\circ}$ AB020399 e $n^{\circ}$ AB020395). As reações apresentaram sensibilidade para detecção de até 1 fg do DNAt de T. solium e 0,2fg do DNAt de T. saginata. A combinação dos primers TBR-3/TBR-4 e TBR3/TBR-6 e o tamanho dos

\begin{abstract}
fragmentos gênicos obtidos permitiram o estabelecimento de ensaios de duplex-PCR, eficaz na detecção simultânea do DNA de $\boldsymbol{T}$. saginata e $\boldsymbol{T}$. solium em sistema único de reação. $O$ s primers utilizados não geraram qualquer produto de amplificação cruzada quando testados com DNAt de Taenia hydatigena, Taenia taeniaeformis, Hymenolepis diminuta, Anoplocephala magna, Paranoplocephala mamillana e Moniezia expansa, nem frente ao DNAt dos hospedeiros Homo sapiens, Bos taurus e Sus scrofa.
\end{abstract}

Palavras-chave: Taenia saginata, Taenia solium, teníase, cisticercose, PCR, duplex-PCR.

\begin{abstract}
This study was conducted to evaluate a protocol and to select novel primers for the species-specific identification of Taenia saginata and Taenia solium by PCR and duplexPCR assays. Sequences of the LSU rRNA gene of taenids were obtained from the GenBank (T. saginata access $n^{\circ}$ AB020399 and T. solium access $n^{\circ}$ AB020395). The sequences were aligned and then used for primer design. The generic primer TBR3 (5'ggcttgttgaatggtttgacg- 3') was selected from a conserved region. The T. saginata specific primer TBR-4 (5'cgactcatgaagataaacaaggt-3') as well as $T$. solium specific primers TBR-5 (5'-cggtcgaacagaccataaatct-3') and TBR-6 (5'gctactacacctaaattctaacc- 3') were selected from different semiconserved regions. The selected sequences were examined in for similarities with other organisms through the GenBank Blast procedure and experimentally by PCR using total DNA (tDNA)
\end{abstract}

${ }^{1}$ Programa de Pós-graduação da Escola de Veterinária da Universidade Federal de Goiás Universidade Federal de Goiás (UFG), Goiania, GO, Brasil.

${ }^{2}$ Escola de Veterinária da Universidade Federal de Goiás (UFG). Campus-II, Setor Samambaia, CEP: 74001-970, Caixa Postal: 131, Goiânia, GO, Brasil. E-mail: guidofcl@ vet.ufg.br. Autor para correspondência.

${ }^{3}$ Departamento de Biologia Celular da Universidade de Brasília (UnB). Brasília, DF, Brasil.

${ }^{4}$ Instituto de Patologia Tropical e Saúde Pública da UFG, Goiânia, GO, Brasil. 
extracted from cysticerci and proglottids from both parasites. The primer pair TBR-3/TBR-4 amplified specific fragments of 328 bp from $T$. saginata $t D N A$. The pairs TBR-3/TBR5 and TBR-3/TBR-6 amplified, respectively, the expected and specific fragments of $310 \mathrm{bp}$ and $286 \mathrm{bp}$ from the $\mathrm{T}$. solium $t D N A$. Sequencing of the amplicons followed by comparison to GenBank reference sequences confirmed the identities of the PCR products. The detection sensitivity was equivalent to $1 \mathrm{fg}$ of T. solium $t D N A$ and $0,2 f g$ of T. saginata $t D N A$. The combination of primers TBR-3/TBR-4 and TBR3/TBR-6 and the size of amplicons allowed the establishment of a duplex-PCR assay to detect T. saginata and T. solium DNA. No cross reaction was observed with any combination of primers in reactions with tDNA of the parasites Taenia hydatigena, Taenia taeniaeformis, Hymenolepis diminuta, Anoplocephala magna, Paranoplocephala mamillana and Moniezia expansa, nether from the hosts tDNA Homo sapiens, Bos taurus nor Sus scrofa.

Key words: Taenia saginata, Taenia solium, teniasis, cisticercosis, PCR, duplex-PCR.

\section{INTRODUÇÃO}

O complexo teníase-cisticercose caracterizase como uma zoonose clássica de grande importância em saúde pública em diversos países do mundo (THEIS et al., 1996; CAIXETA et al., 2004; OIE, 2005) e o diagnóstico dos parasitos envolvidos neste complexo epidemiológico é baseado em métodos convencionais de exame direto e na identificação morfológica das formas parasitárias, sendo que surgem dificuldades na identificação quando as proglotes são imaturas ou degeneradas por processos naturais ou, ainda, porque, mesmo depois de coradas, as ramificações uterinas nem sempre são bem evidenciadas (GOTTSTEIN et al., 1991; MAYTA et al., 2000; MONTERO et al., 2003). Além disso, o exame histológico para a identificação de cisticercos pode conduzir a diagnósticos incorretos (GOTTSTEIN et al., 1991).

A técnica da reação em cadeia da polimerase (PCR), tornou-se a forma mais prática de amplificação de DNA, oferecendo como vantagens sobre os métodos convencionais a rapidez, a especificidade e a elevada sensibilidade, podendo detectar, com precisão, uma simples molécula de DNA na amostra (LISBY, 1999). Atualmente, devido às dificuldades encontradas na identificação de parasitos por métodos convencionais de diagnóstico parasitológico e, diante das vantagens oferecidas pela PCR, o Office International des Epizooties (OIE) tem sugerido que a PCR seja empregada na diferenciação espécie-específica de metacestódeos (OIE, 2005).

Técnicas de biologia molecular têm sido freqüentemente empregadas no diagnóstico de doenças infecciosas e parasitárias. GOTTSTEIN \& MOWATT (1991); GOTTSTEIN et al. (1991) e LOGT \&
GOTTSTEIN (2000) utilizaram a PCR na identificação molecular de $\boldsymbol{T}$. saginata, enquanto MAYTA et al. (2000), para diferenciar T. saginata e T. solium, e THEIS et al. (1996), para detectar o DNA de T. solium, empregaram como método de diagnóstico a caracterização de padrões de digestão enzimática de produtos de PCR. O seqüenciamento dos produtos de PCR foi utilizado por MERI et al. (1999) para a comprovação do diagnóstico da cisticercose. A aplicação da reação de multiplex-PCR para a diferenciação espécie-específica entre $\boldsymbol{T}$. saginata e $\boldsymbol{T}$. solium (GONZÁLEZ et al., 2000; MONTERO et al., 2003; NUNES et al., 2003) já foi reportada. Entretanto, para o diagnóstico espécie-específico de $\boldsymbol{T}$. saginata e/ou $\boldsymbol{T}$. solium, os ensaios descritos e publicados até o momento requerem duas ou mais etapas de reações para que os níveis de especificidade e sensibilidade sejam satisfatórios e resultados conclusivos sejam alcançados.

Este trabalho foi conduzido com o objetivo de selecionar novos primers espécie-específicos a partir de alinhamentos de seqüências do gene que codificam a subunidade ribossômica maior (LSU RNAr) e de estabelecer protocolo para a detecção específica de $\boldsymbol{T}$. solium e/ou $\boldsymbol{T}$. saginata em uma única etapa de reação.

\section{MATERIAL E MÉTODOS}

Os experimentos foram realizados no Laboratório de Biologia Molecular do Departamento de Medicina Preventiva da Escola de Veterinária da UFG. As amostras de parasitos utilizadas provieram da coleção de parasitos do Departamento de Parasitologia da Universidade Federal Rural do Rio de Janeiro e foram identificadas de acordo com NEVEU-LEMAIRE (1936), com base em características morfológicas.

Para as extrações de DNA total (DNAt) dos parasitos foi empregado o kit comercial GenomicPrep $^{\mathrm{TM}}$ Cells and Tissue DNA Isolation Kit (Amersham Biosciences $\left.{ }^{\circledR}\right)$ e, para as extrações do DNA dos hospedeiros, empregou-se o kit comercial GFX ${ }^{\mathrm{TM}}$ Genomic Blood DNA Purification Kit (Amersham Biosciences $^{\circledR}$ ), conforme indicações do fabricante.

A seleção de primers para a amplificação espécie-específica de fragmentos do gene LSU RNAr de $\boldsymbol{T}$. saginata e $\boldsymbol{T}$. solium foi realizada tendo como base os registros sobre seqüências de genes depositadas no banco de dados do GenBank (GENBANK, 2001). Foram então recuperadas informações sobre seqüências do gene LSU RNAr das seguintes espécies da superfamília Taenioidea, com respectivos números de acesso: $\boldsymbol{T}$. saginata 
(AB020396), T. solium (AB020398), T. hydatigena (AB020393), T. crassiceps (AB020399), $\boldsymbol{T}$. taeniaeformis (AB020395) e T. pisiformis (AB020394). $\mathrm{O}$ alinhamento das seqüências foi feito utilizando- se o programa Megalign (LaserGene, DNAStar, Inc.) baseado no método de múltipla progressão de Clustal W (THOMPSON et al., 1994). Os primers foram selecionados de acordo com critérios previamente estabelecidos (FLORIDA STATE UNIVERSITY, 2004). As seqüências selecionadas foram, então, comparadas com seqüências disponíveis no GenBank para avaliação da identidade, através do algoritmo Basic Local Alignment Search Tool - BLAST ${ }^{\circledR}$ (ALTSCHUL et al. 1990). Aquelas que apresentaram resultados satisfatórios quanto à homologia da seqüência de bases, foram encaminhadas a Invitrogen Corp. para a síntese dos oligonucleotídeos correspondentes.

Para controle da especificidade das reações de PCR, foram utilizados DNAt de: Homo sapiens, Bos taurus, Sus scrofa, Taenia hydatigena, Taenia taeniaeformis, Hymenolepis diminuta, Anoplocephala magna, Paranoplocephala mamillana e Moniezia expansa. Como controle positivo, foram utilizadas amostras de DNAt extraídas de proglotes de $\boldsymbol{T}$. saginata e de $\boldsymbol{T}$. solium, cujas características morfológicas eram elucidativas para a determinação da espécie conforme NEVEU-LEMAIRE (1936). Como controle negativo para as misturas das reações, foi utilizada água ultrapura livre de DNA. Com a finalidade de comprovar a identidade molecular dos produtos de PCR (amplicons), estes foram seqüenciados (seqüenciador automático Megabace 1000 - Amersham Biotech ${ }^{\circledR}$ ) e as seqüências obtidas foram comparadas com as seqüências de referência registradas no GenBank (acesso n AB020396 para $\boldsymbol{T}$. saginata e n ${ }^{\circ} \mathrm{AB} 020398$ para $\boldsymbol{T}$. solium).

A preparação da mistura de reação foi feita, adaptando-se procedimentos previamente descritos por INNIS \& GELFAND (1990) ePERSING (1996), como segue: $37,75 \mu 1$ de água ultrapura esterilizada; $5 \mu 1$ de tampão para PCR (PCR buffer 10x - 100mM Tris-HCl, $\mathrm{pH} 9,15 \mathrm{mM} \mathrm{MgCl}_{2}$ e $500 \mathrm{mM} \mathrm{KCl}$ - Amersham Biosciences $^{\circledR}$ ); $1 \mu \mathrm{l}$ de dNTP $10 \mathrm{mM}$ (Amersham Biosciences $\left.^{\circledR}\right) ; 0,5 \mu \mathrm{l}(=10 \mathrm{pM})$ de cada primer; $0,25 \mu \mathrm{l}$

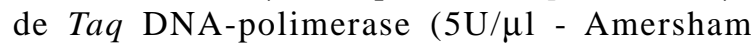
Biosciences $\left.^{\circledR}\right)$; e $5 \mu \mathrm{l}(0,35 \mu \mathrm{g})$ da amostra de DNA. Para a amplificação, os ciclos e as condições de temperatura foram definidos considerando a relação das bases nitrogenadas (GC/AT), conforme reportado por PEREIRA (2003) e FLORIDA STATE UNIVERSITY (2004). A programação para termociclador foi assim estabelecida: um ciclo inicial de desnaturação a $94^{\circ} \mathrm{C}$, por $2 \mathrm{~min}$, seguido de 40 ciclos repetidos de $94^{\circ} \mathrm{C}$, por
$30 \mathrm{~s}, 59^{\circ} \mathrm{C}$, por $30 \mathrm{se} 72^{\circ} \mathrm{C}$, por $1 \mathrm{~min}$, finalizando-se com um ciclo final de extensão a $72^{\circ} \mathrm{C}$, por $5 \mathrm{~min}$.

Para demonstração da viabilidade de detecção simultânea do DNA das duas espécies-alvo em uma única etapa de reação, foi definido um ensaio de duplex-PCR baseado em adaptações no protocolo de PCR descrito acima, como segue: $30,75 \mu 1$ de água ultrapura esterilizada; $5 \mu l$ de tampão para PCR (PCR buffer 10x - 100mM Tris- $\mathrm{HCl}$, pH 9, $15 \mathrm{mM} \mathrm{MgCl}_{2} \mathrm{e}$ $500 \mathrm{mM} \mathrm{KCl}) ; 2 \mu \mathrm{l}$ de dNTP a $10 \mathrm{mM} ; 0,75 \mu \mathrm{l}(10 \mathrm{pM})$ do primer TBR-3, 0,5 $\mu \mathrm{l}(10 \mathrm{pM})$ do primer TBR-4, 0,5 $\mu \mathrm{l}$ (10 pM) do primer TBR-6; 0,5 $\mu \mathrm{l}(5 \mathrm{U} / \mu \mathrm{l})$ de Taq DNApolimerase; e $5 \mu \mathrm{l}(0,35 \mu \mathrm{g})$ de amostra de DNAt extraído de $\boldsymbol{T}$. saginata e $5 \mu \mathrm{l}(0,35 \mu \mathrm{g})$ de amostra de DNAt extraído de $\boldsymbol{T}$. solium.

Os produtos de PCR foram submetidos à eletroforese em gel de agarose a 1,5\% e, em seguida, corados com solução de brometo de etídio a $0,4 \mu \mathrm{g} / \mathrm{ml}$, por imersão. A visualização dos produtos de amplificação foi feita sob luz ultravioleta, em transiluminador (Electronic U. V. Transilluminator, Ultra Lum. Inc. Paramount). Como indicador de massa molecular foi utilizado, em cada corrida de eletroforese, $1 \mu \mathrm{g}$ de marcador de 100pb (100bp DNA Ladder, Invitrogen).

A concentração de DNAt do controle positivo de T. saginata e de T. solium foi determinada por espectrofotometria (GeneQuant pro RNA/DNA calculator, Amersham Pharmacia Biotech) e por estimativa visual em gel de agarose a $1 \%$, utilizando-se como referência o marcador de massa molecularë DNAHind III (Amershan Biosciences ${ }^{\circledR}$ ). Desta forma, determinou-se a concentração de 20ng/(1, para o DNA de $\boldsymbol{T}$. saginata, e de 100ng/(1, para o DNA de $\boldsymbol{T}$. solium. A partir destas amostras, foram feitas diluições seriadas na escala 1:10, com a finalidade de determinar o limiar de sensibilidade da PCR.

\section{RESULTADOS E DISCUSSÃO}

Através do alinhamento do gene do LSU RNAr das espécies T. saginata, T. solium, $\boldsymbol{T}$. hydatigena, T. crassiceps, T. taeniaeformis e $\boldsymbol{T}$. pisiformis foram selecionados quatro primers, os quais foram designados de TBR-3 (primer genérico), TBR-4 (específico para $T$. saginata), TBR-5 e TBR-6 (específicos para T. solium). As seqüências dos primers, assim como as respectivas posições nos genes correspondentes e temperatura de anelamento, são apresentadas na Tabela 1. O par de primers TBR-3/ TBR-4, empregado na amplificação a partir do DNAt de $\boldsymbol{T}$. saginata, e os pares TBR-3/TBR-5 e TBR-3/TBR6, empregados na amplificação a partir do DNAt de $\boldsymbol{T}$. 
Tabela 1 - Seqüências de oligonucleotídeos (primers), selecionados para a amplificação de fragmentos específicos do gene do LSU RNAr de $T$. saginata e $T$. solium pela PCR.

\begin{tabular}{llll}
\hline Primer & \multicolumn{1}{c}{ Seqüência } & Posição & TA \\
\hline TBR-3 (F) & 5'-GGCTTGTTTGAATGGTTTGACG- 3' & $34-55^{* *}$ & $59^{\circ} \mathrm{C}$ \\
TBR-4 (R) & 5'-CGACTCATGAAGATAAACAAGGT-3' & $362-340^{*}$ & $59^{\circ} \mathrm{C}$ \\
TBR-5 (R) & 5'-CGGTCGAACAGACCATAAATCT-3' & $348-327^{*}$ & $59^{\circ} \mathrm{C}$ \\
TBR-6 (R) & 5'-GCTACTACACCTAAATTCTAACC- 3' & $319-297^{*}$ & $59^{\circ} \mathrm{C}$ \\
\hline
\end{tabular}

TBR-3 = primer genérico; TBR-4 = primer específico para $\boldsymbol{T}$. saginata ;BR-5 e TBR-6 = primers específicos para $\boldsymbol{T}$. solium $;(\mathrm{R})=$ reverse primer $;(\mathrm{F})=$ forward primer; $*$ = posição no gene; $* *=$ posição nos genes; $\mathrm{TA}=$ temperatura de anelamento.

solium, apresentaram $100 \%$ de especificidade na amplificação de fragmentos esperados do gene do LSU RNAr, de 328pb, 310pb e 286pb, respectivamente (Figura 1). Nenhuma amplificação inespecífica foi observada a partir do DNAt do hospedeiro definitivo e intermediários, nem a partir do DNAt dos demais tenídeos, utilizados como controles. A identidade específica dos produtos de PCR foi comprovada através do alinhamento de suas seqüências com aquelas utilizadas, nesse estudo, como referência para $\boldsymbol{T}$. saginata e T. solium.

Em relação à identificação espécie-específica de T. saginata por PCR, os resultados obtidos nesse estudo diferem dos apresentados por GOTTSTEIN \& MOWATT (1991), GOTTSTEIN et al. (1991) e por LOGT \& GOTTSTEIN (2000) quanto à especificidade, pois, o par de primers TBR-3/TBR-4, selecionado e avaliado no presente estudo, não amplificou o DNA de nenhum dos tenídeos usados como controle da especificidade, enquanto os primers utilizados por aqueles autores, além de detectarem o DNA de T. saginata, amplificam também fragmentos de DNA de outros tenídeos, inclusive o de T. taeniaeformis.

$\mathrm{O}$ resultado apresentado por MERI et al. (1999) na detecção do DNA de T. solium, assemelha-

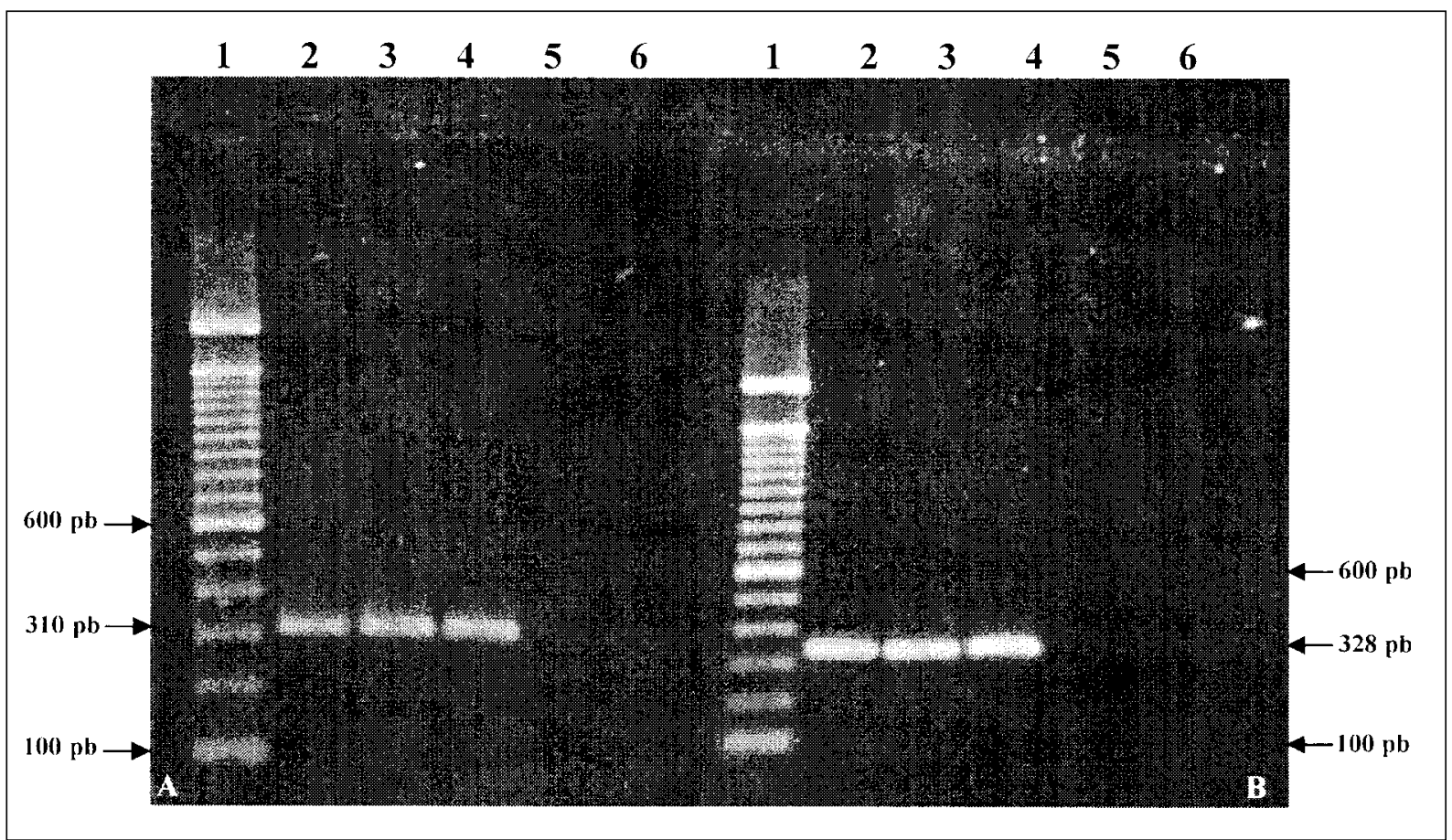

Figura 1 - Eletroforese em gel de agarose a 1,5\% com 10ul de produtos de PCR resultantes da amplificação de fragmentos do gene do LSU RNAr de T. saginata e T. solium para demonstração da especificidade: A. PCR com os primers TBR-3/TBR-5 específicos para T. solium. Marcador de DNA de $100 \mathrm{pb}$ (1); controle positivo (2); DNA de proglote de $\boldsymbol{T}$. solium (3); DNA de Cysticercus cellulosae (4); DNA de T. saginata (5); controle negativo sem DNA (6). B. PCR com os primers TBR-3/TBR4 específicos para $\boldsymbol{T}$. saginata. Marcador de DNA de $100 \mathrm{pb}$ (1); controle positivo (2); DNA de proglote de T. saginata (3); DNA de Cysticercus bovis (4); DNA de T. solium (5); controle negativo sem DNA (6)

Ciência Rural, v.36, n.1, jan-fev, 2006. 
se ao obtido neste estudo quanto à comprovação da identidade através do sequienciamento dos produtos de PCR. No entanto, os resultados não podem ser comparados quanto à especificidade, uma vez que os referidos autores não avaliaram a possibilidade de ocorrência de amplificações inespecíficas a partir do DNA de outras espécies geneticamente relacionadas.

Para demonstração da viabilidade de detecção simultânea do DNA das duas espécies-alvo, os oligonucleotídeos TBR-3/TBR-4/TBR-6 foram utilizados em reação de duplex-PCR com a presença de $5 \mu l$ do DNAt de $\boldsymbol{T}$. saginata e de $5 \mu$ l do DNAt de $\boldsymbol{T}$. solium, permitindo a amplificação dos fragmentos específicos de $328 \mathrm{pb}$ e $286 \mathrm{pb}$, respectivamente (Figura 2). Entretanto, quando se deseja avaliar a presença do DNA de $\boldsymbol{T}$. saginata e/ou de $\boldsymbol{T}$. solium em uma única amostra, como por exemplo, quando da aplicação do ensaio na rotina de diagnóstico laboratorial, deve-se ajustar na preparação da mistura de reação, o volume da amostra de DNA ao da água, para manter o volume final do mix em $50 \mu \mathrm{l}$.

A aplicação do duplex-PCR permitiu a diferenciação entre $\boldsymbol{T}$. solium e $\boldsymbol{T}$. saginata, em uma única etapa de reação, representando assim, significativa vantagem sobre a metodologia de diagnóstico empregada por THEIS et al. (1996) e por MAYTA et al. (2000) que, para a diferenciação espécieespecífica, requer o tratamento do produto de PCR com enzimas de restrição. Esse tipo de metodologia exige maior número de procedimentos laboratoriais, onera o diagnóstico, aumenta o tempo de execução e, conseqüentemente, as possibilidades de erro.

A PCR para $T$. saginata, avaliada neste estudo, com o par de primers TBR-3/TBR-4, demonstrou elevada sensibilidade, permitindo amplificação detectável a partir de 0,2 fg de DNA. A mesma avaliação feita em relação à reação de PCR para $T$. solium, com o par de primers TBR-3/TBR-6, mostrou sensibilidade cinco vezes menor, permitindo amplificação detectável a partir de 1fg (Figura 3). Dos trabalhos revisados, somente nos de GONZÁLEZ et al. (2000) e de NUNES et al. (2003), houve relatos sobre o limiar de sensibilidade da PCR, os quais reportaram a detecção mínima de 10pg de e 1096pg.de DNA, respectivamente. Como se pode verificar, esses limites de detecção foram menos sensíveis que os obtidos no presente estudo. Deve-se ressaltar que, nos experimentos de GONZÁLEZ et al. (2000), assim como no presente estudo, o DNA utilizado para os testes de sensibilidade foi extraído de proglotes, enquanto o DNA utilizado por NUNES et al. (2003) foi extraído de amostras de fezes humanas contaminadas artificialmente com ovos de tênia, estando, provavelmente, mais sujeito à presença de inibidores da PCR.

Entre os trabalhos revisados utilizando- se alguma modalidade de PCR, somente os de MAYTA et al. (2000), GONZÁLEZ et al. (2000), MONTERO et al. (2003) e NUNES et al. (2003) tiveram como objetivo principal, a diferenciação espécie-específica entre $\boldsymbol{T}$.

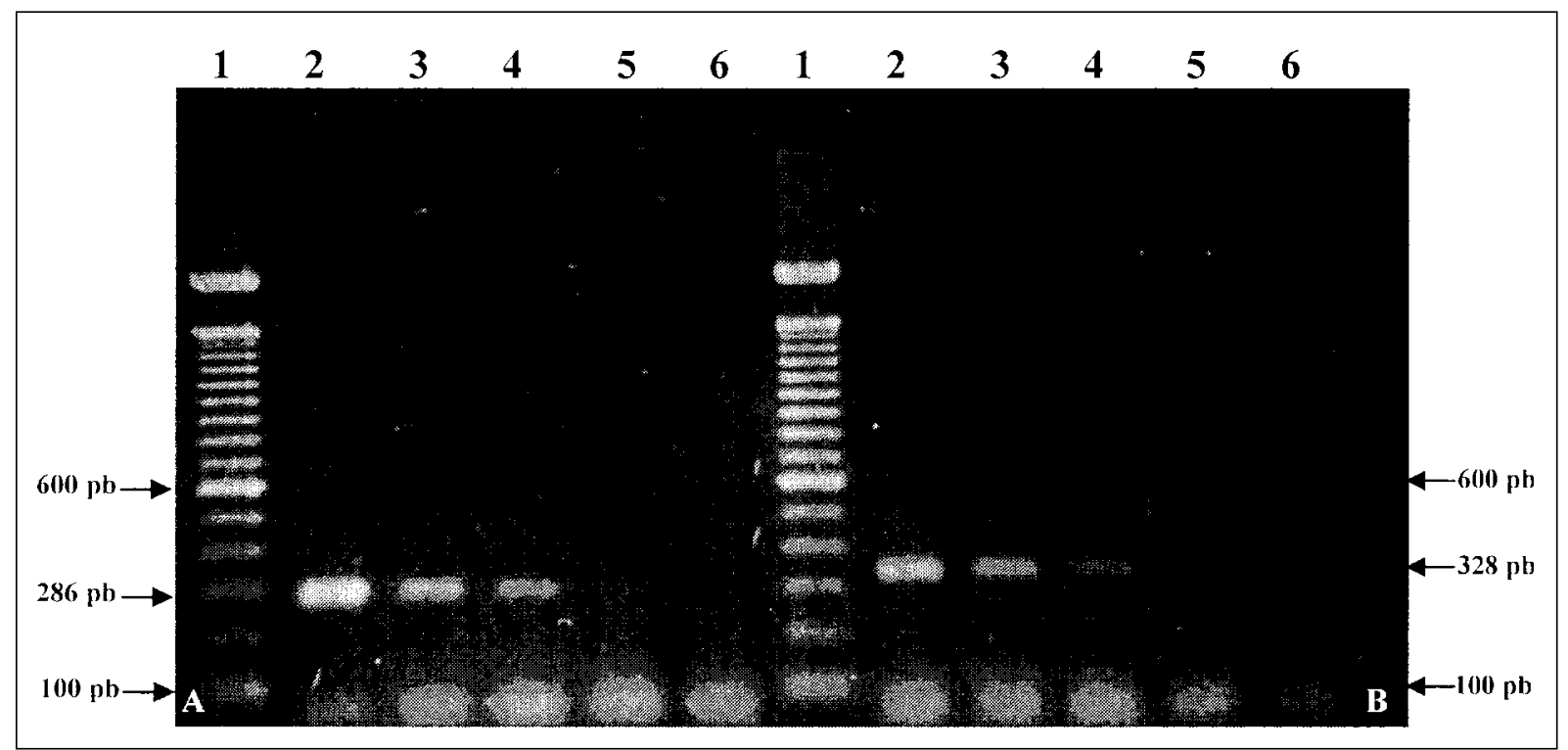

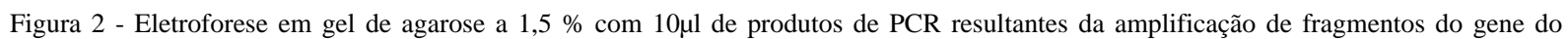
LSU RNAr para demonstração da sensibilidade: A. PCR com os primers TBR-3/TBR-6, específicos para $\boldsymbol{T}$. solium. Marcador de DNA de 100 pb (1); a partir de 100 fg de DNA de $\boldsymbol{T}$. solium (2); $10 \mathrm{fg}$ (3); $1 \mathrm{fg}$ (4); 0,1 fg (5); controle negativo sem DNA (6). B. PCR com os primers TBR-3/TBR-4, específicos para $\boldsymbol{T}$. saginata. Marcador de DNA de $100 \mathrm{pb}$ (1); a partir de $20 \mathrm{fg}$ de DNA de T. saginata (2); $2 \mathrm{fg}$ (3); 0,2 fg (4); 0,02 fg (5); controle negativo sem DNA (6).

Ciência Rural, v.36, n.1, jan-fev, 2006. 


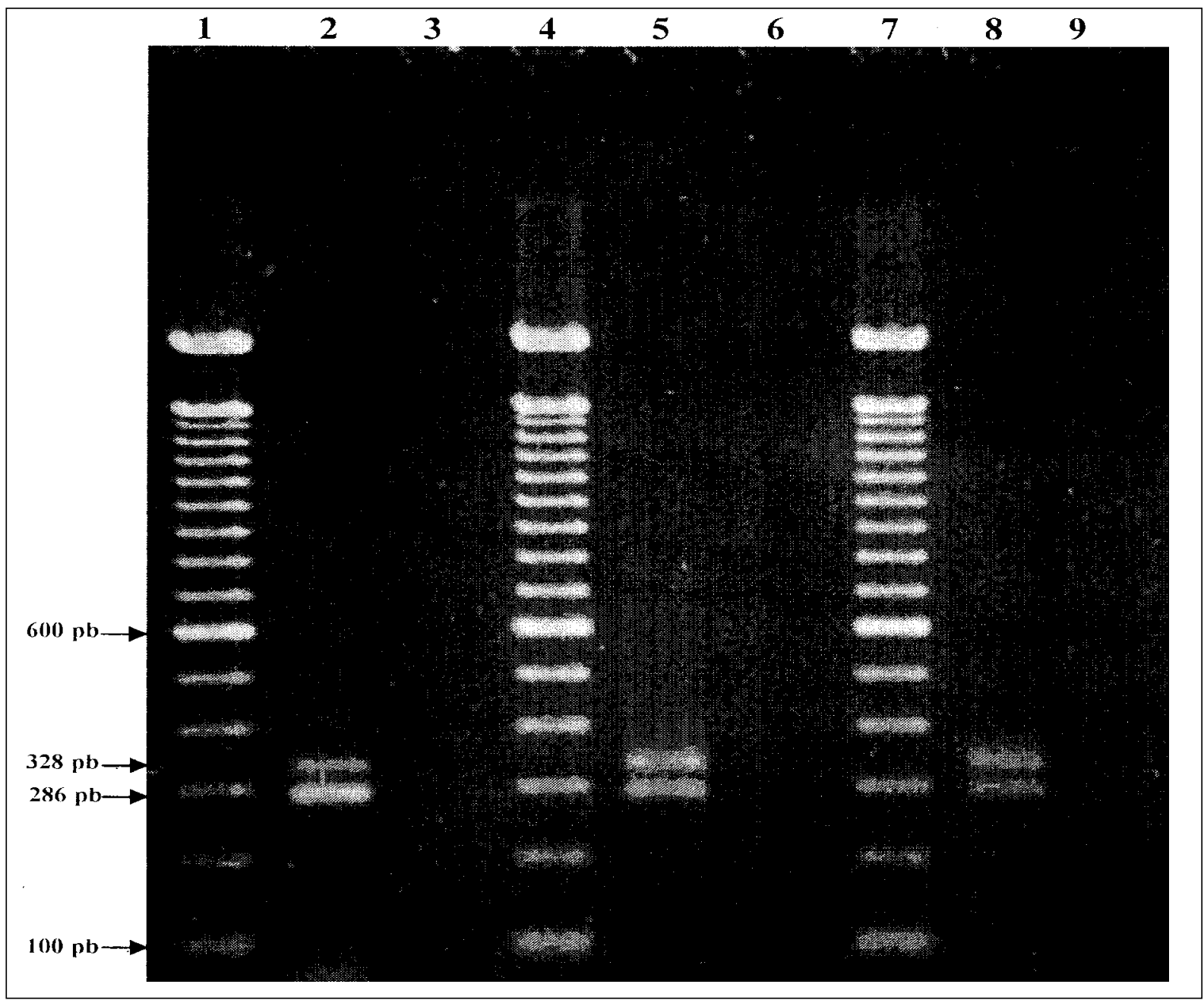

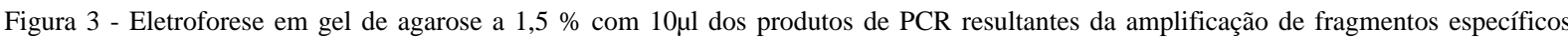
do gene do LSU RNAr de T. saginata e $\boldsymbol{T}$. solium, obtidos por dúplex-PCR utilizando, simultaneamente, o DNAt de $\boldsymbol{T}$. saginata e de T. solium e os primers TBR-3, TBR-4 e TBR-6. Marcador de massa molecular de 100 pb (1, 4 e 7); amplicons de $\boldsymbol{T}$. saginata e de $\boldsymbol{T}$. solium (2, 5 e 8); controle negativo sem DNA (3, 6 e 9)

saginata e $\boldsymbol{T}$. solium, sendo que, GONZÁLEZ et al. (2000), MONTERO et al. (2003) e NUNES et al. (2003) utilizaram a técnica de multiplex-PCR, enquanto MONTERO et al. (2003) e NUNES et al. (2003), empregando os primers desenvolvidos por GONZÁLEZ et al. (2000), obtiveram fragmentos gênicos com o mesmo padrão de amplificação. Considerando-se a necessidade de diferenciação espécie-específica entre $\boldsymbol{T}$. saginata e T. solium, a aplicação dos primers utilizados no presente ensaio de duplex-PCR, quanto à especificidade, apresenta resultados superiores aos da reação de multiplex-PCR descrita por GONZÁLEZ et al. (2000), pelo fato de amplificar fragmentos únicos e distintos. Os primers desenvolvidos por GONZÁLEZ et al. (2000), quando aplicados na PCR com a presença do DNA de $\boldsymbol{T}$. saginata amplificam dois fragmentos gênicos, de 600pb e 170pb, e, quando na presença do DNA de $\boldsymbol{T}$. solium, amplificam um fragmento de $170 \mathrm{pb}$, idêntico, portanto, a um dos fragmentos obtidos para T. saginata. Esse padrão de amplificação pode dificultar a interpretação dos resultados sempre que houver a possibilidade da presença simultânea do DNA das duas espécies na amostra a ser testada, como naquelas provenientes de efluentes sanitários ou, ainda, pela contaminação acidental de DNA entre amostras no laboratório.

Os ensaios de PCR e duplex-PCR, utilizando os novos primers desenvolvidos neste trabalho, constituem-se em alternativa prática e eficaz para condução de estudos clínicos e epidemiológicos, seja na identificação espécie-específica dos parasitos a 
partir da detecção do DNA proveniente de ovos e proglotes presentes em amostras de fezes humanas e/ ou em amostras de efluentes sanitários, seja para estudos que envolvam o diagnóstico da cisticercose animal. Poderão também ser aplicados no esclarecimento da etiopatogenia de lesões cisticercóides, auxiliando o diagnóstico da cisticercose humana ou, ainda, na rotina clínico-laboratorial para a identificação inequívoca de cisticercos e proglotes imaturos ou em processos degenerativos que comprometam o diagnóstico morfológico convencional.

\section{CONCLUSÕES}

O par de primers TBR-3/TBR-4, selecionado e avaliado neste estudo, é eficaz para a identificação espécie-específica de $\boldsymbol{T}$. saginata por PCR. Os pares de primers TBR-3/TBR-5 e TBR-3/TBR-6 são espécieespecíficos na detecção do DNA de T. solium por PCR. A combinação dos primers TBR-3, TBR-4 e TBR-6 permitem a aplicação de ensaio de duplex-PCR para a detecção específica e simultânea de DNA de $\boldsymbol{T}$. saginata e T. solium.

\section{REFERÊNCIAS}

ALTSCHUL, S.F. et al. Basic local alignment search tool. J Mol Biol, v.215, p.403-410, 1990.

CAIXETA, L. et al. Neurocisticercose: forma psíquica e demência. Rev Patol Trop, v.33, n.1, p.33-44, 2004.

FlORIDA STATE UNIVERSITY. Primer design. Capturado em 13 jan. 2004. On line. Disponível na Internet http:// www.bio.fsu.edu/dna_sequencing-primerdesign.php.

GENBANK. Entrez. Nucleotide. Capturado em 22 jan. 2001. On line. Disponível na Internet http://www.ncbi.nlm.nih.gov/.

GONZÁLEZ, M.L. et al. Differential diagnosis of Taenia saginata and Taenia solium Infection by PCR. J Clin Microbiol, v.38, n.2, p.737-744, 2000.

GOTTSTEIN, B. et al. Diagnostic identification of Taenia saginata with the polymerase chain reaction. Trans Royal Soc Trop Med Hyg, v.85, n.2, p.248-249, 1991.
GOTTSTEIN, B.; MOWATT, M. Sequencing and characterization of and Echinococcus multilocularis DNA probe and its use in the polymerase chain reaction. Mol Bioch Parasitol, v.44, n.2, p.183-194, 1991.

INNIS, M.A.; GELFAND, D.H. Optimizations of PCRs. In: INNIS, M.A. et al. PCR protocols - a guide to methods and applications. London: Academic, 1990. Cap.1, p.3-12.

LISBY, G. Application of nucleic acid amplification in clinical microbiology. Molec Biotech, v.12, p.75-89, 1999.

LOGT, P.B.; GOTTSTEIN, B. Unidentified parasitic cysts in cattle. Vet Rec, v.146, p.610-612, 2000.

MAYTA, H. et al. Differentiating Taenia solium and Taenia saginata infections by simple hematoxylin-eosin staining and PCR-restriction enzyme analysis. J Clin Microbiol, v.38, n.1, p.133-137, 2000.

MERI, T. et al. Diagnosis of atypical neurocysticercosis by polymerase chain reaction analysis: case report. Clin Inf Dis, v.28, n.6, p.1331-1332, 1999.

MONTERO, E. et al. Diagnóstico de teniasis humanas mediante PCR-multiplex. Med Clin (Barc), v.120, n.1, p.37-39, 2003.

NEVEU-LEMAIRE, M. Traité d'helminthologie médicale et vétérinaire. Paris: Vigot Frères, 1936. 1514p.

NUNES C.M. et al. Taenia saginata: polymerase chain reaction for taeniasis diagnosis in human fecal samples. Exp Parasitol, v.104, p.67-69, 2003.

O.I.E. Manual of diagnostic tests and vaccines for terrestrial animals. Chapter 2.10.1. Cystcercosis. Capturado em 13 jan. 2005. On line. Disponível na Internet http://www.oie.int/ eng/normes/mmanual/A_00127.htm.

PERSING, D. PCR protocols for emerging infectious diseases. Washington: ASM, 1996. 180p.

PEREIRA, I.S. Amplificação de DNA por PCR. In: AZEVEDO, M.O. et al. Técnicas básicas em biologia molecular. Brasília: Universidade de Brasília, 2003. Cap.6, p.99-110.

THEIS, J.H. et al. DNA-confirmed Taenia solium cysticercosis in black bears (Ursus americanus) from California. Am J Trop Med Hyg, v.55, n.4, p.456-458, 1996.

THOMPSON, J.D. et al. Clustal W: improving the sensitivity of progressive multiple sequence alignment through sequence weighting, positive-specific gap penalties and weight matrix choice. Nucleic Acids Res, v.22, p.4673-4680, 1994. 